\title{
Dutch founder SDHB exon 3 deletion in patients with pheochromocytoma-paraganglioma in South Africa
}

\author{
Debra M Gordon'1, Pablo Beckers², Emilie Castermans², Sebastian J C M M Neggers ${ }^{3}$, Liliya Rostomyan ${ }^{4}$, \\ Vincent Bours ${ }^{2}$, Patrick Petrossians ${ }^{4}$, Vinciane Dideberg ${ }^{2}$, Albert Beckers ${ }^{4}$ and Adrian F Daly ${ }^{4}$ \\ 'University of the Witwatersrand (WITS) Donald Gordon Medical Centre, Parktown, Johannesburg, South Africa \\ 2Department of Human Genetics, Centre Hospitalier Universitaire de Liège, Liège Université, Liège, Belgium \\ ${ }^{3}$ Department of Endocrinology, Erasmus University Medical Center, Rotterdam, The Netherlands \\ ${ }^{4}$ Department of Endocrinology, Centre Hospitalier Universitaire de Liège, Liège Université, Liège, Belgium \\ Correspondence should be addressed to A F Daly: adrian.daly@ulg.ac.be
}

\begin{abstract}
Objective: Screening studies have established genetic risk profiles for diseases such as multiple endocrine neoplasia type 1 (MEN1) and pheochromocytoma-paraganglioma (PPGL). Founder effects play an important role in the regional/national epidemiology of endocrine cancers, particularly PPGL. Founder effects in the Netherlands have been described for various diseases, some of which established themselves in South Africa due to Dutch emigration. The role of Dutch founder effects in South Africa has not been explored in PPGL.

Design: We performed a single-center study in South Africa of the germline genetic causes of isolated/syndromic neuroendocrine tumors. Methods: Next-generation panel, Sanger sequencing and multiplex ligand-dependent probe amplification for endocrine neoplasia risk genes.

Results: From a group of 13 patients, we identified 6 with PPGL, 4 with sporadic or familial isolated pituitary adenomas, and 3 with clinical MEN1; genetic variants were identified in 9/13 cases. We identified the Dutch founder exon 3 deletion in SDHB in two apparently unrelated individuals with distinct ethnic backgrounds that had metastatic PPGL. Asymptomatic carriers with this Dutch founder SDHB exon 3 deletion were also identified. Other PPGL patients had variants in SDHB, and SDHD and three MEN1 variants were identified among MEN1 and young-onset pituitary adenoma patients. Conclusions: This is the first identification of a Dutch founder effect for PPGL in South Africa. Awareness of the presence of this exon 3 SDHB deletion could promote targeted screening at a local level. Insights into PPGL genetics in South Africa could be achieved by studying existing patient databases for Dutch founder mutations in $S D H x$ genes.
\end{abstract}

Key Words

- SDHB

- founder mutation

- paraganglioma

- pheochromocytoma

- South Africa

- Dutch

- Netherlands

\section{Introduction}

The role of germline genetic factors in neuroendocrine/ endocrine neoplasias has advanced significantly in recent decades with the identification of novel genetic causes for inheritable isolated and syndromic tumors. This is particularly true in the case of pheochromocytomas and paragangliomas (PPGL) (1). These neuroendocrine tumors produce symptoms due to direct tumor effects and the synthesis and release of bioactive amines, neurotransmitters, and hormones; about 20 new germline and somatic genetic factors have been discovered in https://ec.bioscientifica.com

https://doi.org/10.1530/EC-21-0560 (c) 2022 The authors Published by Bioscientifica Ltd

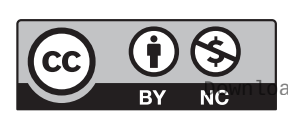

This work is licensed under a Creative Commons Attribution-NonCommercial 4.0 International License. ded from Bioscientifica.com at 04/26/2023 01:48:44PM 
recent decades (1). Among the best-characterized genetic causes of PPGL are pathological variants involving genes encoding succinate dehydrogenase (SDH) subunits, SDHA, $S D H B, S D H C, S D H D$, and $S D H A F$ (collectively referred to as $S D H x$ ). Disruption by mutation or epimutation of $S D H x$ genes leads to a state of cellular pseudohypoxia due to abnormal regulation of the Krebs cycle, accumulation of cancer-inducing metabolites, and subsequent activation of multiple targets of HIF1 $\alpha$. SDHx germline pathological variants are a major cause of familial disease, and $S D H B$ accounts for about $10 \%$ of familial cases and has a relatively high risk of metastasis.

Genetic testing regimes are in place internationally for the diagnosis and characterization of genetic forms of PPGL. National datasets have identified high prevalences of particular pathological SDHx variants in defined geographical regions due to founder effects. For instance, endemic disease due to a p.Tyr114Cys $S D H D$ variant in the Mocheni valley close to Trentino, Italy, was found to originate from a common, probably Germanic, founder 600-700 years ago (2). Other founder effects have been reported in SDHx genes in Spain, Portugal, and Quebec - Canada $(3,4,5)$. The strong influence of highly prevalent founder $S D H x$ mutations on the national epidemiology of PPGL is well typified by the experience of the Netherlands (6). In a large national survey ( $n=1045$ DNA samples), Hensen et al. reported that among 690 cases/carriers with a mutation in SDHx genes, a full $89 \%$ had one of six Dutch founder mutations (7). In the Netherlands, the SDHD founder mutations, c. $274 \mathrm{G}>\mathrm{T}$ and p.Asp92Tyr, accounted for almost $70 \%$ of all SDHx carriers/cases (7). SDHB mutations play a concomitantly lower role in the epidemiology of PPGL in the Netherlands, although $S D H B$ founders have also been described there (8). In that study, Bayley and colleagues reported nine apparently unrelated Dutch patients that all had an exon 3 deletion. The patients had extra-adrenal and head and neck paragangliomas, pheochromocytomas, and pituitary adenomas; only one had a family history of PPGL (8). All nine patients shared haplotypes around $S D H B$ and had identical breakpoint sequences, proving a common founder.

While founder effects can lead to an elevated regional/ national prevalence of a particular $S D H x$ mutation among PPGL cohorts, such individuals can 'seed' new geographic foci in line with patterns of population expansion and emigration. From the late 16th century, Dutch exploration and trade led to the establishment of settlements and colonies throughout Asia, Africa, and the Americas. In South Africa, a number of genetic diseases in the population have been tied to founder effects derived from early settlers from the Netherlands (9). Whereas other founder effects are well established in South Africa and most PPGL in the Netherlands are accounted for by founder SDHx mutations, to date, no Dutch founder effect has been demonstrated in PPGL patients in South Africa. Indeed, there is a general paucity of genetic risk information for PPGL and other endocrine-related cancers throughout sub-Saharan Africa $(10,11,12)$. As part of a 2-year collaborative study, we examined the genetic causes of different endocrine and neuroendocrine tumors in a single center in South Africa. We identified multiple individuals with genetic forms of endocrine tumors, including two apparently unrelated individuals with the Dutch founder SDHB exon 3 deletion.

\section{Patients and methods}

The study population consisted of patients under the care of one author in Johannesburg, South Africa (DG), that had diagnoses of aggressive or familial neuroendocrine tumors. For inclusion, patients had to have a clinical or family history consistent with the following syndromes: MEN1, MEN2, MEN4, McCune-Albright syndrome, Carney complex, familial isolated pituitary adenomas (FIPA), and familial isolated hyperparathyroidism. Patients with sporadic or syndromic PPGL or early onset pituitary adenomas (<30 years) were also eligible for inclusion. Genetic studies were undertaken using genomic DNA from the index cases. When a pathological variant in a potential risk gene was found, genetic testing of potential carriers in the family was also offered. Family inquiries regarding geographic origins were undertaken.

Genetic studies utilized a combination of panel-based next-generation sequencing (NGS) and Sanger sequencing for genes of interest: multiplex ligand-dependent probe amplification (MLPA) was used to assess for the presence of whole or partial gene deletions. The panel of genes assessed included: $A I P, M E N 1, C D K N 1 B, S D H A, S D H B, S D H C, S D H D$, SDHAF2, VHL, and RET and MAX. The following SALSA MLPA (MRC-Holland, Amsterdam, the Netherlands) was used for MLPA analyses: P244, P016, P429, and P226. NGS was amplicon-based. Briefly, all the coding exons of each gene were amplified during first PCR with specifically designed primers in four multiplex PCRs. A second PCR was performed to incorporate the molecular identifiers and adaptors in the generated fragments. The amplicons were quantified, pooled, and run on a Miseq Sequencer (Illumina).

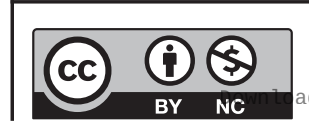

This work is licensed under a Creative Commons Attribution-NonCommercial 4.0 International License. ded from Bioscientifica.com at 04/26/2023 01:48:44PM 


\section{Breakpoint sequencing}

For each patient presenting a deletion of SDHB exon 3 on the P226 MLPA, a specific PCR was performed using the following primers:

\section{SDHB-delE3F: GTAATCCCAACATTCTGAGAGG} SDHB-delE3R: TTAAAGCCACTGTTATTTGAAC

The primers were checked for the presence of common SNPs and were blasted. The primers hybridize at intron 2 (between exons 2 and 3) and at intron 3 (between exons 3 and 4). This design allows a PCR amplification only in patients with the deletion and generates a 262bp fragment. Sequencing was performed on an ABI 3500XL, and data analysis was performed with Seqpilot 3.5.2 and Seqnext 4.3.1 (JSI Medical systems, Ettenheim, Germany)

\section{Ethics approval}

The study was approved by the Ethics Committees of the University of Liège, Belgium, and the University of the Witwatersrand, South Africa. All patients and relatives provided informed written consent.

\section{Results}

Assessment of clinical characteristics in the study center population identified 13 index individuals that met the inclusion criteria and underwent genetic studies (Table 1). There were six index patients with PPGL identified at the study center. Of these, two had a positive family history and the rest were clinically sporadic. In five of the six index cases, a pathological genetic variant was discovered by NGS/ Sanger screening: four patients had an $S D H B$ pathological variant and another had an $S D H D$ variant. For $S D H B$, two unrelated patients P06 and P07 were heterozygous for c.201-4429_287-934del (p.Cys68Hisfs*22), a class 5 pathogenic variant. This variant leads to a large deletion, encompassing exon 3 of $S D H B$, and causes a frameshift and premature stop codon in exon 4. P07 had an extraadrenal paraganglioma that recurred with metastases postoperatively. The variant was not present in the mother and one child of patient P07 (two other unaffected children carried the variant); P07 had two brothers who died of PPGL previously and a sister who had been diagnosed recently with PPGL in another country. Patient P06, who has a metastatic pheochromocytoma from a young age (Fig. 1), had no family members who wished to undergo screening.

The SDHB exon 3 deletion c.201-4429_287-934del was originally described as a Dutch founder mutation. Given the established role of Dutch founder mutations in the causation of inherited diseases in South Africa, we hypothesized that the $S D H B$ exon 3 deletion might similarly be due to a founder effect. P06 and P07 shared no known family links, with P06 coming from the historical multiracial ethnic group characteristic of the Western Cape and elsewhere $(13,14)$. P07 is from an Afrikaner family. On discussion with the affected individuals regarding their geographical origins, no common place or person was identified and searches of church or other records for such links were not feasible due to lack of information. We sequenced the breakpoints around the $S D H B$ exon 3 deletion in a known carrier of this change from the Netherlands. Thereafter, we sequenced the breakpoints of the exon 3 deletion in P06 and P07. As seen in Fig. 2, the exon 3 deletion breakpoints were identical in the patients from the Netherlands and South Africa, which strongly links the cases reported here to the established Dutch founder.

Patient P13 was a clinically sporadic case who had a single neck paraganglioma, who was found to carry a c. $423+1 G>C$ probably pathological splice site variant. Interestingly, a $\mathrm{G}>\mathrm{A}$ change at the same position has been described as a founder mutation in the Netherlands; this abolishes the consensus splice donor sequence and moves the normal splice site into exon 4, thereby deleting 18 amino acids (15). Patient P14 carried a c.287G>A (p.Gly96Asp) class 4 variant in $S D H B$, which was also present in two nieces who were affected with paragangliomas and renal cell carcinoma; her unaffected son was a carrier. P05 who had a bilateral carotid body paraganglioma and rightsided pheochromocytoma (Fig. 3) was found to have a pathological c.337_340delGACT SDHD variant that leads to a predicted p.Asp113Metfs*21 change at the protein level.

Three patients were identified that presented clinically with MEN1. Of these, two had MEN1 variants on sequencing of MEN1, whereas one patient with a pituitary microadenoma, parathyroid hyperplasia, and adrenal adenomas was negative for all genetic studies. The two MEN1 variants were the truncating variant p.Thr210Serfs*13, which has been widely identified in MEN1 cohorts, and the other was a c.824+5G $>$ A change that is considered to be a VUS3 based on its rarity and on in silico prediction of affecting splicing. Among the four pituitary patients, two had FIPA and two were sporadic. One of the sporadic patients had a large, aggressive prolactinoma at a young age (Fig. 3) and was found to have a c.1618C>T; p.Pro540Ser change in MEN1, which has conflicting clinical significance. Among the other patients, no sequence or MLPA changes were seen, including in one patient with young-onset acromegaly and a large 


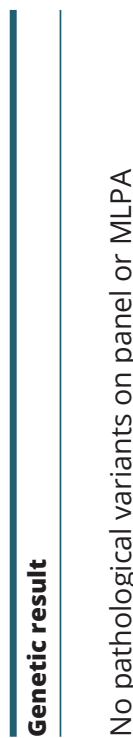

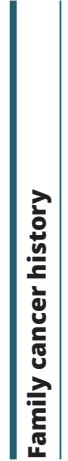

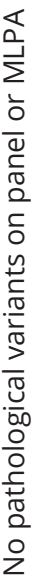

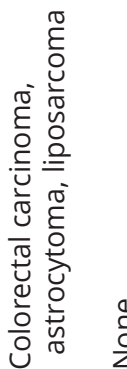

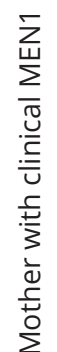
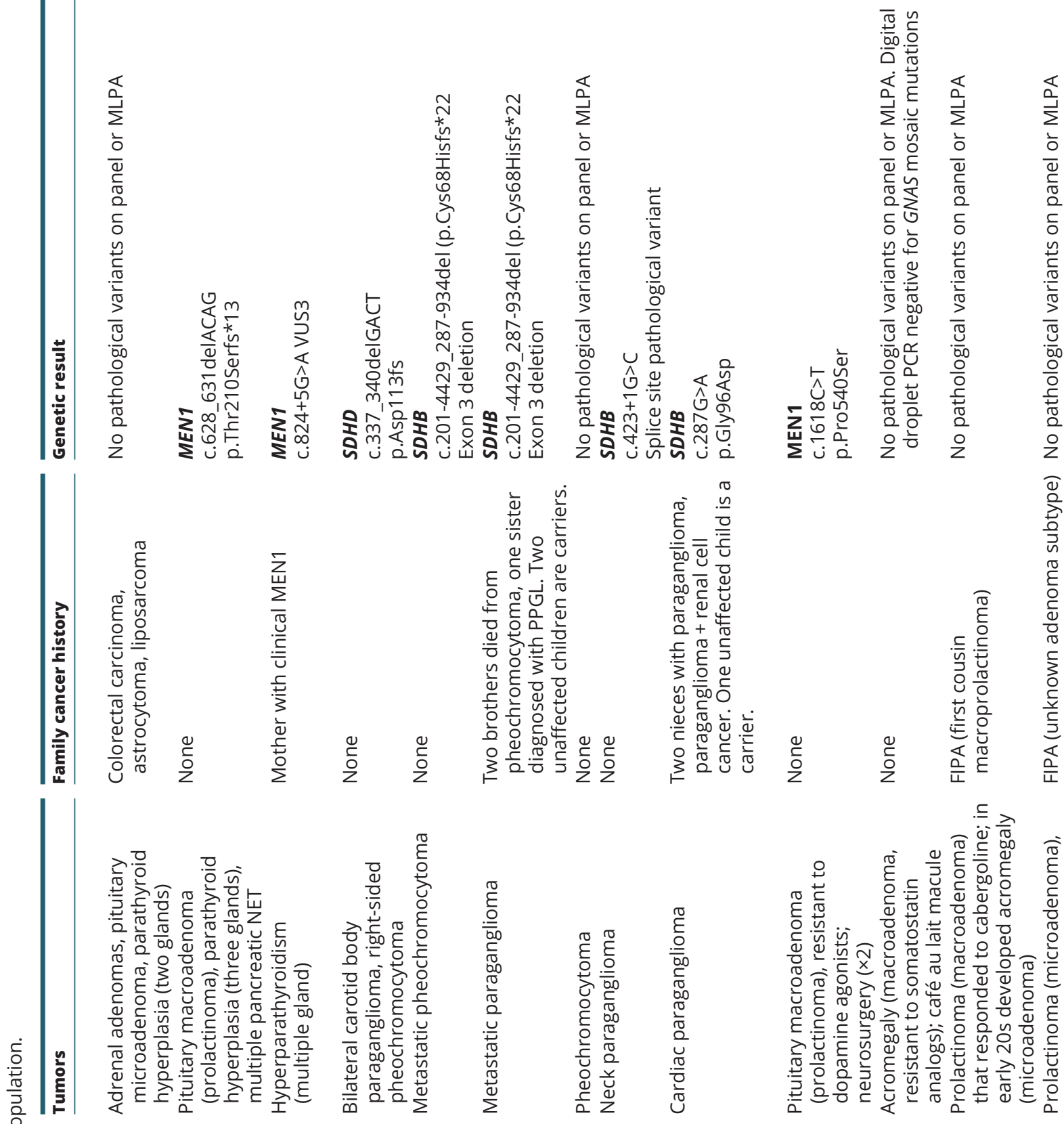

政

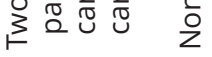
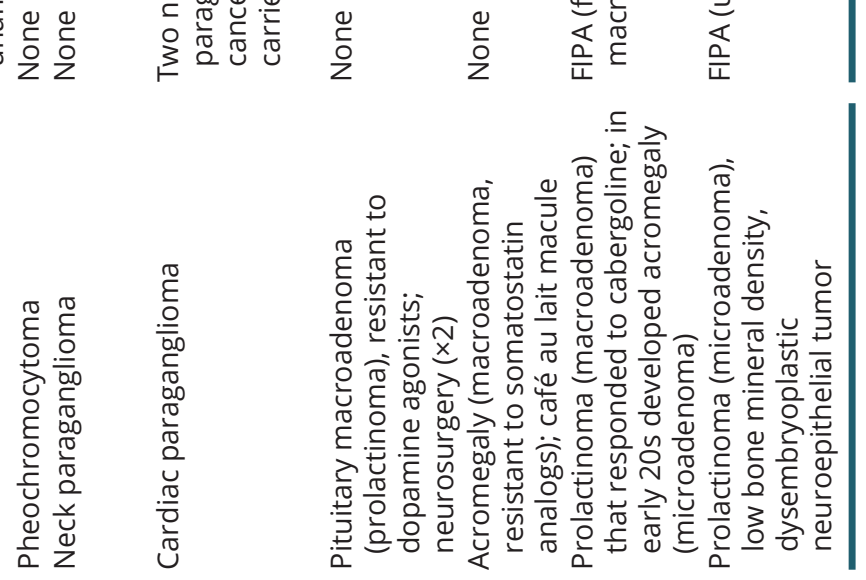

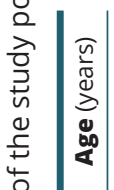

$\stackrel{\infty}{\sim} \stackrel{n}{\sim}$

q

$\stackrel{m}{m} \stackrel{\circ}{m}$

$\mathfrak{6}$

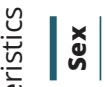

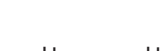

$\Sigma \quad \Sigma$

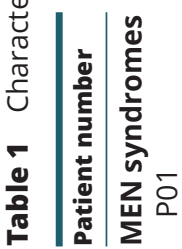

ำ

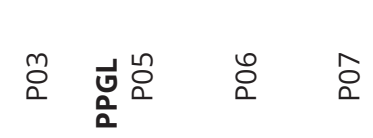

$\stackrel{n}{\frac{m}{a}} \quad \frac{\pi}{a}$

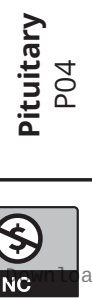

$\bar{\Sigma}$ ล

$\dddot{m}$ 

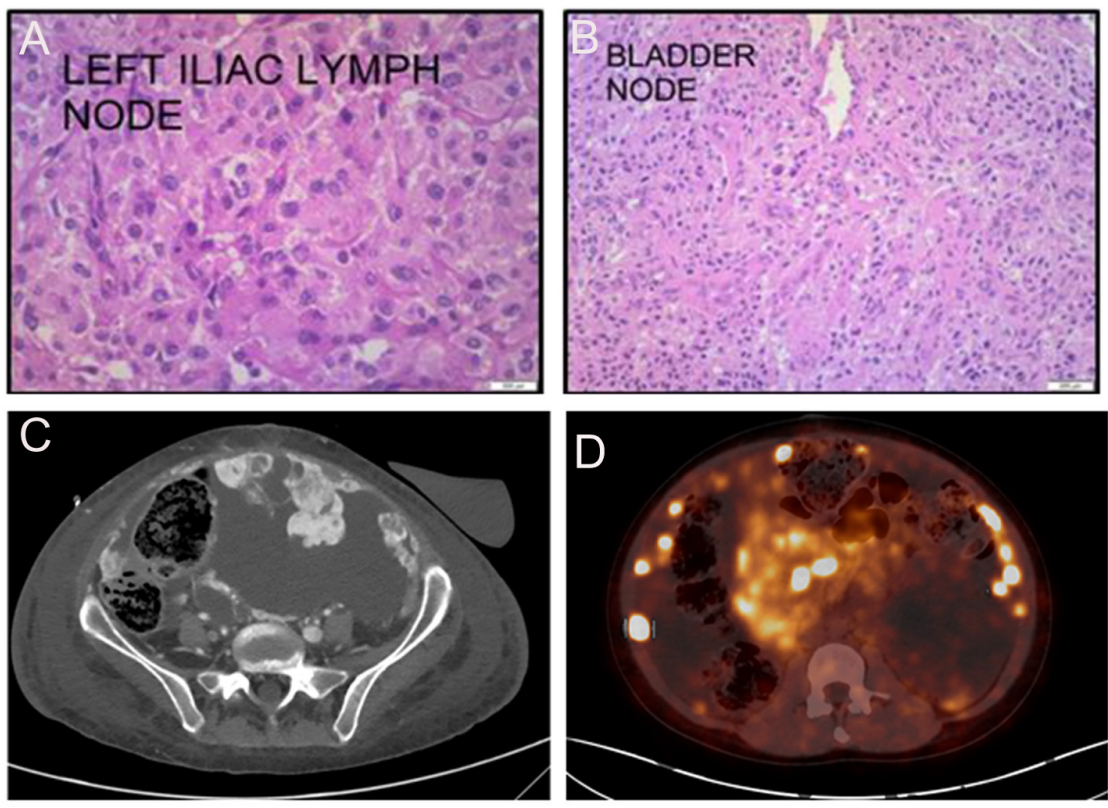

\begin{abstract}
Figure 1
Pathology (A, B) and imaging (C, D) studies in patient P06 with the Dutch founder exon 3 deletion of SDHB. High-power (A) and low-power (B) H\&E staining images of metastatic pheochromocytoma deposits in the iliac and peri-vesicular lymph nodes at presentation. CT (C) and PET-CT (D) images showing metastatic deposits of pheochromocytoma in the pelvic and iliac regions.
\end{abstract}

irregular café au lait macule who also had negative digital droplet PCR for mosaic GNAS mutations underlying McCune-Albright syndrome (16).

\section{Discussion}

Genetic studies are playing a growing role in the clinical investigation and management of various cancers in the developed world. This is true for endocrine neoplasias like PPGL, where a large number of new target genes have been identified recently (17). In the developing world, technological and budgetary constraints conspire to limit greatly the availability and use of clinical genetics, thereby hindering optimal management. For example, in sub-Saharan Africa, despite a significant and growing cancer burden, there is a relative dearth of information about underlying genetic risk profiles among highly heterogeneous populations (18). In South Africa, there is
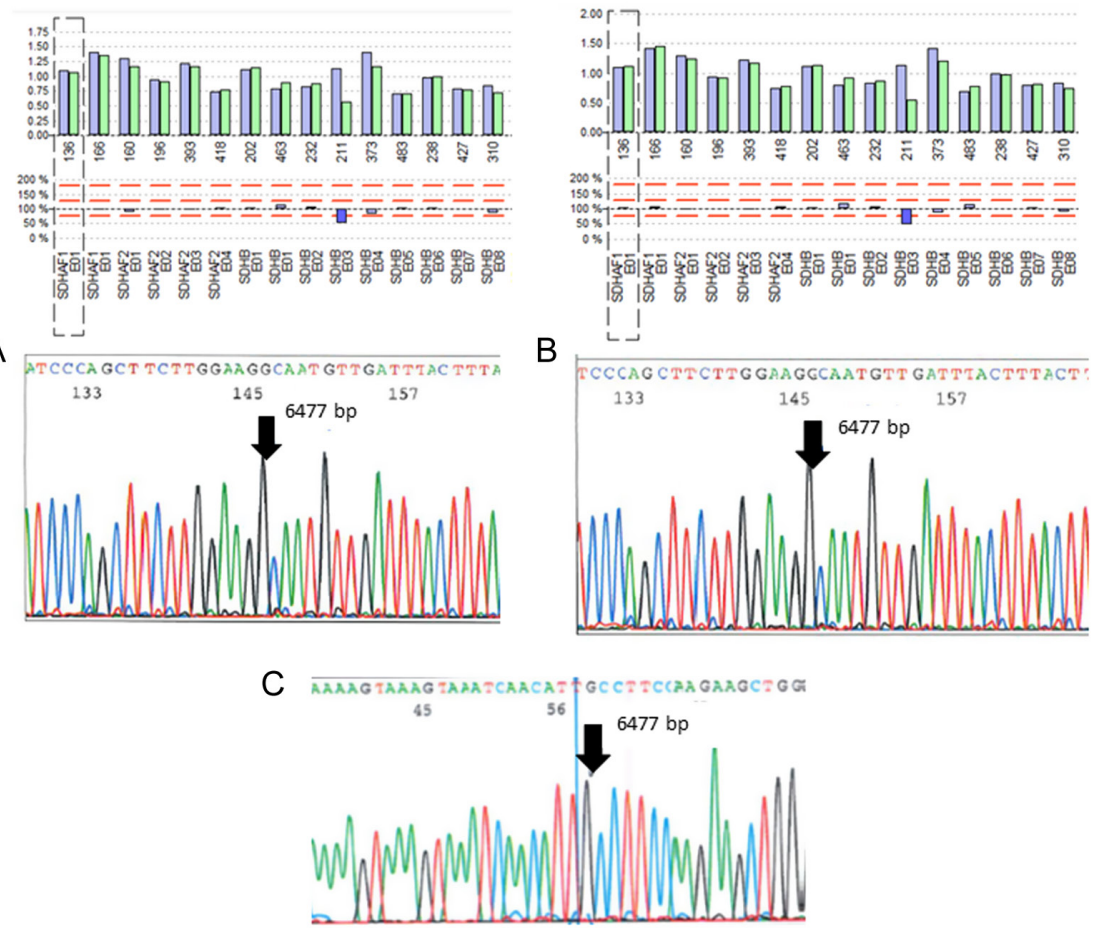

\title{
Figure 2
}

Sequences and MLPA results in two South African individuals with the Dutch founder exon 3 deletion in $S D H B$ (panels A and B). The identical control sequence from an established carrier of the Dutch founder exon 3 SDHB deletion is shown in panel C.

https://ec.bioscientifica.com https://doi.org/10.1530/EC-21-0560

(c) 2022 The authors Published by Bioscientifica Ltd
This work is licensed under a Creative Commons Attribution-NonCommercial 4.0 International License. ded from Bioscientifica.com at 04/26/2023 01:48:44PM 
A

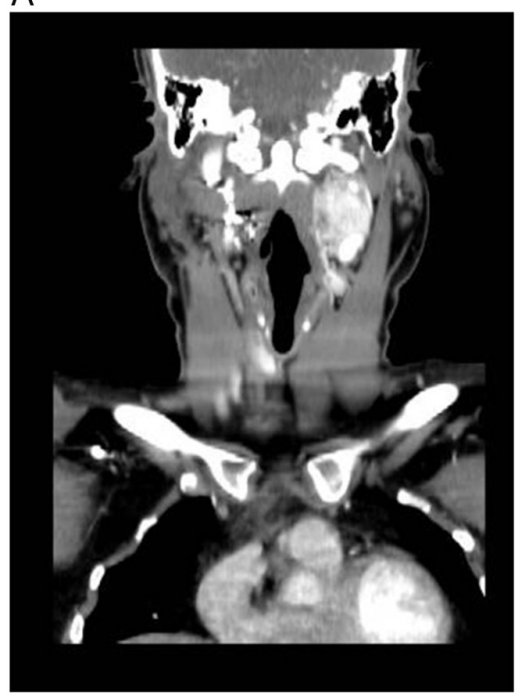

B

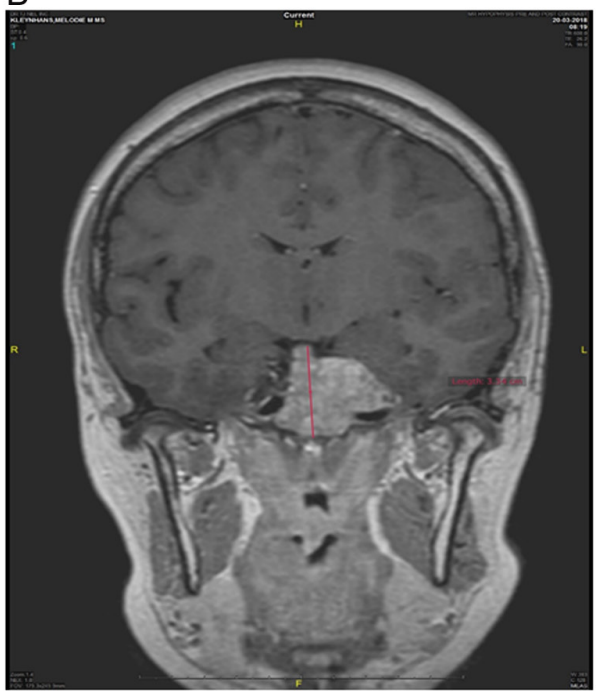

\section{Figure 3}

Panel A shows CT of patient P05 with bilateral carotid body paraganglioma due to a pathogenic germline SDHD variant (c.337_340delGACT; $p$. Asp113fs). Panel B shows a coronal MRI at diagnosis of a sporadic pituitary macroadenoma (prolactinoma) in patient P04 with a MEN1 variant (c.1618C>T; p.Pro540Ser). the added complexity of large numbers of individuals with European, Asian, and mixed heritage in addition to different Black populations. Therefore, the identification of existing genetic risks in European populations and elsewhere is relevant in South Africa. For endocrine neoplasias, large-scale screening in Europe has revealed enrichment of certain mutations (SDHx) among subpopulations (geographic, religious, cultural, and ethnic), leading to endemic PPGL genetic risk profiles $(2,7)$. When carriers emigrate from areas of endemic genetic disease to new regions, they can act as founders of new foci of genetic risk.

In this study, we found a new Dutch founder effect in South Africa, due to the presence of a characteristic SDHB exon 3 deletion causing familial and clinically sporadic PPGL. This exon 3 deletion in SDHB was first described in the Netherlands by Bayley et al. (8). In that study, they described nine apparently unrelated Dutch patients with sporadic PPGL and performed breakpoint analysis at the deletion; all nine had the same sequencing findings. Using an identical approach, we demonstrated a $1.6 \mathrm{~kb}$ PCR product in the two South African PPGL cases and in a known Dutch carrier of the exon 3 SDHB deletion. Sequencing of the breakpoints in the South African cases and in the Dutch case was identical. This finding is unlikely to have occurred due to a mutational hotspot. As noted by Bayley et al., the downstream breakpoint is not located in an Alu repeat region and there are no other features that would make this a likely region for a hotspot (8).

Previous studies in the Netherlands and among populations of Dutch origin worldwide provide some of the best examples of the importance of founder effects in genetic diseases. The Netherlands exemplifies the role of geographic and cultural factors in the establishment and subsequent enrichment of pathological genetic variants in their population (9). Study of Dutch founder mutations has shown that some arose within culturally, geographically, and family determined genetic isolates within the Netherlands. As religious and cultural limitations loosened in the 20th century and the Dutch population increased, these founder mutations came to play an important role nationally in genetic disease epidemiology (9). PPGL genetics is a good example of this. The overwhelming majority of PPGL in the Netherlands are derived from specific SDHD mutations, particularly c.274G $>\mathrm{T}$ and c. $416 \mathrm{~T}>\mathrm{C}$ (6). Indeed, nearly $89 \%$ of all $S D H x$ carriers in the Netherlands have one of six founder mutations in $S D H D$, $S D H B$, and SDHAF; the $S D H B$ exon 3 deletion is one of these $(6,7,19)$. Emigration of Dutch settlers to colonies in South Africa, the Americas, and elsewhere led to the establishment of new concentrations of carriers of founder mutations in various genes. In South Africa, numerous well-described examples of Dutch founder effects in diseases related to hypercholesterolemia and porphyria have even revealed the likely identity of the founder centuries before. The current study strongly suggests that an SDHB founder mutation might be playing a similar role in PPGL pathophysiology in South Africa.

The penetrance of $S D H B$ mutation-related PPGL is variable (25-75\%); data from large kindreds suggest that even the low end of this range may well be a significant overestimate (20). This low penetrance would explain the lack of a recognized family history of PPGL in patient P06, which echoes the sporadic presentation of the nine Dutch PPGL patients in the original report of the SDHB exon 3 deletion founder (8). Identification of this founder effect in South Africa is clinically relevant, as the patients and

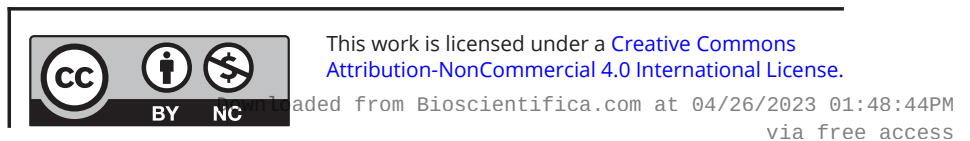


families affected in this study had an aggressive phenotype. Further study of previously identified patients with PPGL in South Africa could provide more information on the relative frequency of the exon 3 deletion $S D H B$ founder mutation $(10,21,22)$.

Other genetic causes of PPGL in the current study include a truncating SDHD c.337_340delGACT (p.Asp113Metfs ${ }^{*} 21$ ) change in a sporadic male of Asian origin with bilateral head and neck paraganglioma and pheochromocytoma. This pathological variant had been identified in various sporadic and familial PPGL cohorts from Asturias (Spain), India, and the Netherlands (7, 23, 24). Another patient with a European Jewish background had a family history of PPGL in two nieces and all three shared the same c.287G $>$ A (p.Gly96Asp) SDHB change; this missense change was previously reported in the United States and elsewhere $(25,26,27)$. Among the patients with presentations typical of MEN1, in two cases previously identified MEN1 variants were found in germline DNA. In the patients with FIPA or isolated aggressive pituitary adenomas, no variants in AIP were seen, which is in keeping with the known genetic epidemiology of these populations (28). One aggressive prolactinoma was noted in a young patient who had a variant of unknown significance in MEN1; there is a known association between MEN1 variants and youngonset pituitary adenomas (29).

The study has a number of limitations. As a small single-center cohort, we cannot determine the overall structure of the genetic risk profile for endocrine neoplasias, including PPGL in South Africa as a whole, similar to previous genetic studies on this topic in South Africa $(10,11,12,22)$. Hence, it remains to be proven in larger series whether the $S D H B$ exon 3 deletion mutation plays a major role in PPGL risk nationally in South Africa. Also, the limited study size means that the potential presence in South Africa of other important Dutch founder SDHx mutations, particularly SDHD c.274G>T, remains to be established. Similarly, the presence of $S D H B$ exon 3 deletion in other Dutch emigrant populations will need to be specifically addressed.

In conclusion, this 2-year study of endocrine neoplasia populations at a single center in South Africa identified multiple patients with MEN, PPGL, and pituitary adenomas with clinically actionable genetic variants. In particular, we identified for the first time the presence of the known Dutch founder $S D H B$ exon 3 deletion among apparently unrelated PPGL patients in South Africa. This extends the acknowledged role of Dutch founder mutations in disease in South Africa into the field of inherited neuroendocrine tumors, including pheochromocytomas and paragangliomas. Wider screening programs of PPGL patients in South Africa could help to ascertain the relative importance of this and potentially other $S D H x$ gene founder mutations derived from historical Dutch emigration.

\section{Declaration of interest}

The authors declare that there is no conflict of interest that could be perceived as prejudicing the impartiality of the research reported.

\section{Funding}

The study was supported in part by a grant from the Fonds pour la recherche scientifique (FIRS), CHU de Liege 2017-2020.

\section{Acknowledgements}

The authors would like to acknowledge Dr Carli MJ Tops, Dr Jean-Pierre Bayley, and Dr Frederik Hes of the Departments of Clinical Genetics and Human Genetics, Leiden University Medical Center for their valuable guidance regarding Dutch founder SDHB mutations and Dr Manuel Van Den Venter from Lancet Laboratory in South Africa and Dr June Fabian from the Research Department of WITS Donald Gordon Medical Centre for ther assistance in conducting the study analyses.

\section{References}

1 Papathomas TG, Suurd DPD, Pacak K, Tischler AS, Vriens MR, Lam AK \& de Krijger RR. What have we learned from molecular biology of paragangliomas and pheochromocytomas? Endocrine Pathology 2021 32 134-153. (https://doi.org/10.1007/s12022-020-09658-7)

2 Schiavi F, Dematte S, Cecchini ME, Taschin E, Bobisse S, Piano A Del, Donner D, Barbareschi M, Manera V, Zovato S, et al. The endemic paraganglioma syndrome type 1: origin, spread, and clinical expression. Journal of Clinical Endocrinology and Metabolism 201297 E637-E641. (https://doi.org/10.1210/jc.2011-2597)

3 Bourdeau I, Grunenwald S, Burnichon N, Khalifa E, Dumas N, Binet MC, Nolet S \& Gimenez-Roqueplo AP. A SDHC founder mutation causes paragangliomas (PGLs) in the French Canadians: new insights on the SDHC-related PGL. Journal of Clinical Endocrinology and Metabolism 2016101 4710-4718. (https://doi.org/10.1210/jc.2016-1665) 4 Cascón A, Pita G, Burnichon N, Landa I, López-Jiménez E, MonteroConde C, Leskelä S, Leandro-García LJ, Letón R, Rodríguez-Antona C, et al. Genetics of pheochromocytoma and paraganglioma in Spanish patients. Journal of Clinical Endocrinology and Metabolism 200994 1701-1705. (https://doi.org/10.1210/jc.2008-2756)

5 Martins RG, Nunes JB, Máximo V, Soares P, Peixoto J, Catarino T, Rito T, Soares P, Pereira L, Sobrinho-Simões M, et al. A founder SDHB mutation in Portuguese paraganglioma patients. Endocrine-Related Cancer 201320 L23-L26. (https://doi.org/10.1530/ERC-12-0399)

6 Hensen EF, Siemers MD, Jansen JC, Corssmit EPM, Romijn JA, Tops CMJ, Mey AGL Van Der, Devilee P, Cornelisse CJ, Bayley JP, et al. Mutations in SDHD are the major determinants of the clinical characteristics of Dutch head and neck paraganglioma patients. Clinical Endocrinology 201175 650-655. (https://doi.org/10.1111/j.13652265.2011.04097.x)

7 Hensen EF, Duinen N van, Jansen JC, Corssmit EPM, Tops CMJ, Romijn JA, Vriends AHJT, van der Mey AGL, Cornelisse CJ, Devilee P, et al. High prevalence of founder mutations of the succinate dehydrogenase genes in the Netherlands. Clinical Genetics 201281 284-288. (https://doi.org/10.1111/j.1399-0004.2011.01653.x) 
8 Bayley JP, Grimbergen AEM, van Bunderen PA, van der Wielen M, Kunst HP, Lenders JW, Jansen JC, Dullaart RPF, Devilee P, Corssmit EP, et al. The first Dutch SDHB founder deletion in paragangliomapheochromocytoma patients. BMC Medical Genetics 20091034. (https://doi.org/10.1186/1471-2350-10-34)

9 Zeegers MPA, Poppel F van, Vlietinck R, Spruijt L \& Ostrer H. Founder mutations among the Dutch. European Journal of Human Genetics 2004 12 591-600. (https://doi.org/10.1038/sj.ejhg.5201151)

10 Bruce-Brand C \& Van Wyk AC. Prevalence of succinate dehydrogenase deficiency in paragangliomas and phaeochromocytomas at a tertiary hospital in Cape Town: a retrospective review. Journal of Endocrinology, Metabolism and Diabetes of South Africa 202126 9-15. (https://doi.org/1 0.1080/16089677.2020.1838161)

11 Shone D, Goedhals J \& Pearce NE. Malignant paraganglioma in an African patient associated with a succinate dehydrogenase subunit B (SDHB) mutation. South African Journal of Surgery 201856 64-66. (https://doi.org/10.17159/2078-5151/2018/V56N2A2391)

12 Siddiqui N, Seedat F, Bulbulia S, Mtshali NZ, Botha A, Krause A, Daya R $\&$ Bayat Z. SDHB-associated paraganglioma syndrome in Africa - a need for greater genetic testing. Journal of the Endocrine Society 20215 bvab111. (https://doi.org/10.1210/jendso/bvab111)

13 Quintana-Murci L, Harmant C, Quach H, Balanovsky O, Zaporozhchenko V, Bormans C, Helden PD van, Hoal EG \& Behar DM. Strong maternal Khoisan contribution to the South African coloured population: a case of gender-biased admixture. American Journal of Human Genetics 201086 611-620. (https://doi.org/10.1016/j.ajhg.2010.02.014)

14 Statistics South Africa. Mid year population estimates 2019 (STATISTICAL RELEASE P0302). Pretoria, South Africa: Statistics South Africa , 2019. (available at: https://www.statssa.gov.za/publications/ P0302/P03022019.pdf)

15 Bayley JP, Minderhout I van, Weiss MM, Jansen JC, Oomen PHN, Menko FH, Pasini B, Ferrando B, Wong N, Alpert LC, et al. Mutation analysis of SDHB and SDHC: novel germline mutations in sporadic head and neck paraganglioma and familial paraganglioma and/or pheochromocytoma. BMC Medical Genetics 20067 1. (https://doi. org/10.1186/1471-2350-7-1)

16 Vasilev V, Daly AF, Thiry A, Petrossians P, Fina F, Rostomyan L, Silvy M, Enjalbert A, Barlier A \& Beckers A. McCune-Albright syndrome: a detailed pathological and genetic analysis of disease effects in an adult patient. Journal of Clinical Endocrinology and Metabolism 201499 E2029-E2038. (https://doi.org/10.1210/jc.2014-1291)

17 Juhlin CC. Challenges in paragangliomas and pheochromocytomas: from histology to molecular immunohistochemistry. Endocrine Pathology 202132 228-244. (https://doi.org/10.1007/s12022-021-09675-0)

18 Rotimi SO, Rotimi OA \& Salhia B. A review of cancer genetics and genomics studies in Africa. Frontiers in Oncology 202010606400. (https://doi.org/10.3389/FONC.2020.606400)

19 Taschner PEM, Jansen JC, Baysal BE, Bosch A, Rosenberg EH, Bröcker-Vriends AHJT, Mey AGL Van Der, Ommen GJB Van, Cornelisse CJ \& Devilee P. Nearly all hereditary paragangliomas in the Netherlands are caused by two founder mutations in the SDHD gene. Genes, Chromosomes and Cancer 200131 274-281. (https://doi. org/10.1002/gcc.1144)

20 Rijken JA, Niemeijer ND, Corssmit EPM, Jonker MA, Leemans CR, Menko FH \& Hensen EF. Low penetrance of paraganglioma and pheochromocytoma in an extended kindred with a germline SDHB exon 3 deletion. Clinical Genetics 201689 128-132. (https://doi. org/10.1111/cge.12591)

21 Huddle KR. Phaeochromocytoma in black South Africans - a 30-year audit. South African Medical Journal 2011101 184-188. (https://doi. org/10.7196/SAMJ.4320)

22 Nel D, Panieri E, Malherbe F, Steyn R \& Cairncross L. Surgery for pheochromocytoma: a single-center review of 60 cases from South Africa. World Journal of Surgery 202044 1918-1924. (https://doi. org/10.1007/s00268-020-05420-6)

23 Lima J, Feijão T, Ferreira da Silva A, Pereira-Castro I, FernandezBallester G, Máximo V, Herrero A, Serrano L, Sobrinho-Simões M \& Garcia-Rostan G. High frequency of germline succinate dehydrogenase mutations in sporadic cervical paragangliomas in Northern Spain: mitochondrial succinate dehydrogenase structure-function relationships and clinical-pathological correlations. Journal of Clinical Endocrinology and Metabolism 200792 4853-4864. (https://doi. org/10.1210/jc.2007-0640)

24 Kapoor N, Pai R, Ebenazer A, Sen I, Stephen E, Agarwal S, Paul MJ \& Rajaratnam S. Familial carotid body tumors in patients with sdhd mutations: a case series. Endocrine Practice 201218 e106-e110. (https:// doi.org/10.4158/EP12012.CR)

25 Brouwers FM, Eisenhofer G, Tao JJ, Kant JA, Adams KT, Linehan WM \& Pacak K. High frequency of SDHB germline mutations in patients with malignant catecholamine-producing paragangliomas: implications for genetic testing. Journal of Clinical Endocrinology and Metabolism 200691 4505-4509. (https://doi.org/10.1210/ jc.2006-0423)

26 Ghayee HK, Havekes B, Corssmit EPM, Eisenhofer G, Hammes SR, Ahmad Z, Tessnow A, Lazúrová I, Adams KT, Fojo AT, et al. Mediastinal paragangliomas: association with mutations in the succinate dehydrogenase genes and aggressive behavior. Endocrine-Related Cancer 200916 291-299. (https://doi.org/10.1677/ERC-08-0214)

27 Benn DE, Gimenez-Roqueplo AP, Reilly JR, Bertherat J, Burgess J, Byth K, Croxson M, Dahia PL, Elston M, Gimm O, et al. Clinical presentation and penetrance of pheochromocytoma/paraganglioma syndromes. Journal of Clinical Endocrinology and Metabolism 200691 827-836. (https://doi.org/10.1210/jc.2005-1862)

28 Vandeva S, Daly AF, Petrossians P, Zacharieva S \& Beckers A. Somatic and germline mutations in the pathogenesis of pituitary adenomas. European Journal of Endocrinology 2019181 R235-R254. (https://doi. org/10.1530/EJE-19-0602)

29 Cuny T, Pertuit M, Sahnoun-Fathallah M, Daly A, Occhi G, Odou MF Tabarin A, Nunes ML, Delemer B, Rohmer V, et al. Genetic analysis in young patients with sporadic pituitary macroadenomas: besides AIP don't forget MEN1 genetic analysis. European Journal of Endocrinology 2013168 533-541. (https://doi.org/10.1530/EJE-12-0763)

Received in final form 14 December 2021

Accepted 23 December 2021

Accepted Manuscript published online 23 December 2021 https://ec.bioscientifica.com https://doi.org/10.1530/EC-21-0560 (c) 2022 The authors Published by Bioscientifica Ltd

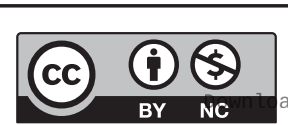

This work is licensed under a Creative Commons Attribution-NonCommercial 4.0 International License. ded from Bioscientifica com at 04/26/2023 01:48:44PM 